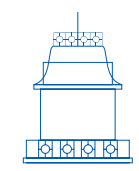

ARTÍCULOS

DE INVESTIGACIÓN

\title{
Transhumanismo: Un giro de tuerca a la pregunta por la técnica de Heidegger*
}

\author{
Diana María Muñoz González \\ Universidad de San Buenaventura, Bogotá, Colombia \\ E-mail:dmunoz@usbbog.edu.co
}

Recibido: 31 de mayo de 2019 | Aprobado: 28 de octubre de 2019

https://doi.org/10.17533/udea.ef.n61a10

\begin{abstract}
Resumen: El llamado transhumanismo es un proyecto antropotécnico que pretende aumentar las facultades físicas y cognitivas del ser humano mediante el empleo intensivo de las nuevas tecnologías. No obstante, examinado bajo la lente del pensamiento de Heidegger tal proyecto confirma la idea del filósofo alemán de que la técnica moderna es un dispositivo ontológico en el que la totalidad de los entes es emplazada como existencias o recursos explotables. Así pues, en un primer momento el artículo se sirve de la reflexión heideggeriana sobre la técnica para exhibir el peligro de deshumanización que envuelve al proyecto transhumanista. En un segundo momento, en cambio, se pone al descubierto la limitación de su pensamiento para salir al paso de manera aún más eficaz frente al peligro del transhumanismo al rehusarse a afirmar el carácter esencialmente viviente del ser humano.
\end{abstract}

Palabras clave: Heidegger, transhumanismo, humanismo, técnica, cuerpo humano

* Este artículo es producto del proyecto de investigación "Ser humano en la era técnica: el desafío filosófico del transhumanismo", desarrollado en el Grupo de Investigación "Devenir” de la Universidad de San Buenaventura, el cual está reconocido en COLCIENCIAS con código COL0047323.

Cómo citar este artículo:

Muñoz González, D. M. (2020). Transhumanismo: un giro de tuerca a la pregunta por la técnica de Heidegger. Estudios de filosofía, 61, 145-166. https://doi.org/10.17533/udea.ef.n61a10

\section{OPEN 2 ACCESS}




\title{
Transhumanism: A turn of the screw on Heidegger's question concerning technology
}

\begin{abstract}
The so-called transhumanist project is an anthropotechnic and aims at the enhancement of human physical and cognitive capabilities through the employment of new technologies. Nevertheless, when viewed through the lens of Heidegger's philosophy, the project appears to confirm his own view on modern technology. According to Heidegger, the essence of modern technology is to serve as an ontological framework in which beings are unconcealed as a totality of resources or stock items. Thus, the first part of this paper examines Heidegger's approach to technology in order to cast light upon the deep danger of dehumanization entailed by transhumanism. In the second section, however, the ability of Heidegger's thought to cope with the transhumanist danger is put into question, since it fails to conceive of the essential living character of human being.
\end{abstract}

Key words: Heidegger, transhumanism, humanism, technology, human body

\section{Diana María Muñoz González}

Doctora en Filosofía por la Universidad París VIII (Francia), con títulos de Pregrado y Magister en Filosofía de la Universidad Nacional de Colombia. Actualmente es Profesora Titular de la Universidad de San Buenaventura, sede Bogotá, en la Maestría en filosofía contemporánea y el Doctorado en Humanidades: Humanismo y Persona -DHUPE-, programa en el que se desempeña como directora del énfasis en filosofía denominado: "Humanismo y antihumanismo en la filosofía contemporánea". Es Investigadora Asociada ante Colciencias y lidera el grupo de investigación "Devenir" (A1). Algunas de sus publicaciones son: Libros: Arte y verdad. La experiencia estética en la hermenéutica de Hans-Georg Gadamer (2013), ¿El fin del hombre? (2016) (Ed.) y Humanismo en la era de la técnica (2018) (Ed.). Artículos: "Las humanidades en tiempos del Antropoceno" (2019), "Deconstrucción y teología negativa» (2014), «El texto como modelo de alteridad" (2014) y "Nietzsche y los filósofos de la diferencia" (2013). 
A juzgar por el importante número de publicaciones, tanto especializadas como divulgativas que cada día se suman a la discusión acerca del transhumanismo, no parece excesivo afirmar que este proyecto antropotécnico, así como la ideología que hay detrás de él, ha ganado ya un lugar prioritario en la agenda del pensamiento crítico de nuestro siglo. El interés y la polémica que genera no paran de crecer. Ocurre en el ámbito académico donde ha pasado de ser considerado mera ciencia ficción, a ser tenido por un signo clave del espíritu de la época, caracterizada como ninguna otra por el culto a la técnica (Hunyadi, 2018). Pasa otro tanto en el campo político donde, como sugieren sendos reportes auspiciados en años recientes por el gobierno estadounidense y por la Unión Europea, aumenta la inquietud frente a las potencialidades, así como posibles amenazas, de una empresa que, con un tono utópico muy propio, pero respaldada por millones de dólares, se propone cambiar para siempre la historia de la humanidad (Hottois, 2016). ${ }^{1}$ No es para menos todo este revuelo, ya que el sueño del transhumanismo aparece tan prometedor como alarmante. Según como se lo vea, su ideal de lograr el perfeccionamiento tecnológico del ser humano nos ofrece, cual figura del dios Jano, dos facetas bastante contrarias: unas veces de esperanza, otras veces de espanto, empañando más, si cabe, nuestra visión de un futuro que cada vez se muestra más incierto.

En este artículo nos interesa examinar la propuesta del transhumanismo bajo la lente del pensamiento de Martin Heidegger, cuya penetrante manera de reflexionar sobre el fenómeno de la técnica le ha valido ocupar un lugar prominente en la discusión filosófica sobre el tema. Pese a que el pensador alemán no conoció muchos de los adelantos que hoy en día les permiten a los transhumanistas enarbolar sus utópicas promesas -como son los avances en ingeniería genética o en inteligencia artificial, de los que cada día recibimos noticias más asombrosas-, no cabe duda de que su meditación acerca de la esencia de la técnica le permitió avizorar con lucidez la manera como el afán de dominio de la técnica moderna llevaría a convertir a los seres humanos en la siguiente frontera a ser conquistada (Heidegger, 1994). Ciertamente, la perspectiva heideggeriana habrá anticipado con acierto algunos de los peligros que entraña la deriva híper-tecnológica a la que asistimos en la actualidad, siendo quizás el transhumanismo una confirmación más de cuán fundados eran esos temores.

Sin embargo, pese a la clarividencia del "Oráculo de Friburgo", no podemos dejar de plantearnos la siguiente pregunta: ¿está su llamado a salvaguardar nuestra humanitas del peligro de la técnica a la altura del desafío que actualmente nos lanza el transhumanismo? En lo que sigue nos interesa sugerir que la renuencia del filósofo alemán a pensar el carácter biológico, natural, animal, en suma, viviente del ser humano, dada su preocupación por evitar el reduccionismo biologicista, puede a la

1 Como bien anota este autor francés, tales reportes dan cuenta de la visibilidad política que ha alcanzado el transhumanismo desde el inicio del nuevo milenio. 
postre constituir un límite muy serio para quien, siguiendo sus pasos, desee tomar posición crítica frente a los retos que trae consigo el transhumanismo. Efectivamente, este límite, que no es otro sino el relacionado con su rechazo a pensar el ser humano en su condición de viviente, obliga a cuestionar a fondo la comprensión que la filosofía heideggeriana tiene del cuerpo humano, comprensión que quizás termina por acercarlo -seguramente a pesar del mismo Heidegger - a una tradición humanista usualmente inclinada a ignorar la corporeidad humana en nombre de una supuesta trascendencia a la que, en honor a su especial dignidad, el ser humano estaría llamado a "elevarse" más allá de su mera condición de ser vivo.

\section{El transhumanismo como proyecto antropotécnico}

Comencemos por recordar, a grandes rasgos, lo que propone el transhumanismo. En palabras del filósofo francés Luc Ferry se trata de un "amplio proyecto de mejora de la humanidad actual en todos sus aspectos, físico, intelectual, emocional y moral, gracias a los progresos de las ciencias, y en particular de las biotecnologías" (Ferry, 2017, p. 35). En efecto, se lee en el "Manifiesto Transhumanista" lo siguiente: "Nos planteamos la posibilidad de ampliar el potencial humano superando el envejecimiento, las lagunas cognitivas, el sufrimiento involuntario y nuestro aislamiento en el planeta Tierra" (Ferry, 2017, p. 38). Si bien estas declaraciones altisonantes podrían ser tenidas por fantasías de tecno-eufóricos a las que no habría que dar mucho crédito, lo cierto es que "el proyecto -continúa diciendo Ferry- ya está en marcha en los laboratorios, en las universidades, en los centros de investigación y las grandes empresas, en Estados Unidos o en China" (Ferry, 2017, p. 39). En otras palabras, el transhumanismo se muestra como algo más que una simple ilusión quimérica de unos cuantos soñadores, al gozar de un sólido respaldo financiero suministrado por corporaciones multinacionales que, como el gigante de Internet, Google, y otras compañías más ancladas en el poderoso Silicon Valley, aseguran cuantiosos recursos a centros de investigación comprometidos con esta prometeica idea.

Más que una vaga esperanza, a sus patrocinadores les anima la firme convicción de que las nuevas tecnologías, como son las nanotecnologías, las biotecnologías, las ciencias de la informática y la cibernética (usualmente reunidas en la sigla NBIC), no solo corregirán, curarán o repararán serios problemas de salud física y/o mental que afectan el desarrollo de los seres humanos, sino que, más aún -y es aquí donde reside el sello distintivo del transhumanismo-, aumentarán o incrementarán las capacidades cognitivas o físicas de los seres humanos sanos: el Ilamado human enhancement. Julian Huxley, padre del término "transhumanismo" (Huxley, 1957), ${ }^{2}$ lamentaba lo pequeña que

2 El término es atribuido a Julian Huxley, quien en un artículo de 1957 escribió: "The human species can, if it wishes, transcend 
a su parecer era la fracción del potencial mental alcanzado por los seres humanos -en palabras suyas, la "spiritual efficiency" - y evocaba con el término por él acuñado el vasto campo de posibilidades que gracias a la ciencia y la tecnología estaba todavía por explorar y que permitiría a los seres humanos desarrollar posibilidades inimaginables.

$Y$ es que para el proyecto transhumanista resulta esencial diluir la línea pretendidamente nítida entre una práctica médica terapéutica y una práctica de mejoramiento. Es decir, borrar la diferencia entre, por un lado, una medicina enfocada en curar a quien está enfermo o padece alguna anomalía física y/o mental y, por otro lado, una práctica que busca aumentar o crear capacidades que están más allá del límite considerado estándar para un ser humano sano. En cierto modo, subyace a esta distinción la que a la sazón trazara Aristóteles en la Física (2000, 194a 21; 199a 15) entre la techné como imitación de la physis y la techné como complemento de la physis, esto es, entre una técnica que produce artefactos inspirados en la perfección atribuida a un modelo natural y otra que, en cambio, busca con sus productos completar los vacíos, o hasta concluir lo que la naturaleza habría dejado apenas a medias (Aristóteles, 2002). En el primer caso, la naturaleza es tomada como el ideal que impone su medida al quehacer de la técnica, mientras que en el segundo es prácticamente sinónimo de lo contrario: de una carencia intrínseca que, desde luego, tendría que ser superada mediante la técnica. De suerte que la cuestión está sobre todo, para el transhumanismo, en hacer lo que por sí sola y sin intervención humana, la naturaleza no parece capaz de llevar a término, o al menos no al ritmo que algunos desearían. Así lo deja plasmado el transhumanista Max More cuando escribe:

Madre Naturaleza, verdaderamente te estamos agradecidos por lo que has hecho por nosotros. Sin duda alguna, has puesto en ello lo mejor de tus fuerzas. Pero, sin querer faltarte al respeto, en lo que concierne a la constitución del hombre, no siempre has hecho un buen trabajo (More, 2013, p. 449; traducción libre).

Ahora bien, a pesar de lo cuestionable que puede parecer (en especial por motivos éticos) que desaparezca dicha distinción, no es fácil negar la dificultad objetiva que hay en dibujar una separación clara e inequívoca entre una práctica solamente terapéutica y una práctica de tipo mejorativo. ${ }^{3}$ ¿No tienden acaso a confundirse conforme avanza

itself — not just sporadically, an individual here in one way, an individual there in another way, but in its entirety, as humanity. We need a name for this new belief. Perhaps transhumanism will serve: man remaining man, but transcending himself, by realizing new possibilities of and for his human nature" (Huxley, 1957, pp. 13-17).

3 A ese respecto, conviene recordar aquí la reflexión de Jürgen Habermas acerca de la dificultad para distinguir entre lo que él llama un eugenismo negativo (terapéutico) y un eugenismo positivo (mejorativo), dificultad que según sugiere no parece posible superar de forma definitiva: "En la medida en que por razones conceptuales y prácticas, esta línea de demarcación [entre eugenismo negativo y eugenismo positivo] es fluctuante, lo que previamente apuntaba a contener las intervenciones genéticas más acá de la frontera más allá de la cual estaríamos en presencia de mejoras de las características genéticas, nos confronta, no obstante, a un desafío paradójico, puesto que nos vemos llevados hasta un campo donde precisamente las fronteras son fluctuantes, teniendo que establecer e imponer líneas de demarcación particularmente precisas. He ahí 
la medicina? ¿Sobre qué base decir, por ejemplo, que una vacuna es tan solo un recurso terapéutico y no también uno de mejoramiento, si quien la recibe obtiene una inmunidad que de lo contrario no tendría en su condición natural? ¿Cómo no hablar de mejoramiento si la vacuna disminuye, o incluso hace desaparecer la vulnerabilidad ante ciertos patógenos, condición de partida en la que todos los humanos se encuentran al nacer? En fin, ¿acaso el individuo vacunado no cuenta con capacidades que en cierto modo mejoran su desempeño? Desde luego, mucho de la lectura que se haga de estos casos depende de la manera como se defina, en el plano filosófico, lo que significa tener una capacidad o ser capaz de algo; pero, en cualquier caso, parece plausible seguir hasta cierto punto la intuición del sentido común acerca de que, antes que curar un padecimiento existente, es decir, antes que curar una enfermedad, lo que la vacuna busca realmente es impedir que se la sufra y, vistas así las cosas, ¿no es esto mejorar en cierto modo al individuo que en principio está sano?

Es probable que ante un caso como este se pueda encontrar una salida teórica más o menos fácil de cara a la aparente confusión que suscita entre terapia y mejoramiento, ya que, en últimas, lo que podemos decir que se persigue con las vacunas es evitar patologías que podrían limitar o acabar una vida sana, de manera que con la vacuna el individuo siga gozando, gracias a este recurso, de una existencia que está siendo perfectamente normal. Pero las cosas se oscurecen cuando nos encontramos con dispositivos o técnicas empleados, no porque la salud o la vida del individuo estén o puedan estar comprometidas por carecer de tales soportes, sino, por ejemplo, cuando se emplean para aumentar la capacidad de memoria, de percepción, de movimiento, de resistencia al esfuerzo, etc., es decir, cuando se acude a ellos para romper los límites considerados normales para alguien de nuestra especie. Y es justamente esta, como veíamos, la pretensión transhumanista: desplazar "hacia adelante" la frontera de lo que un miembro promedio de nuestra familia humana es capaz de hacer.

A primera vista, semejante aspiración parece implicar, como sostienen los transhumanistas, el abandono de toda idea de naturaleza humana que pudiera, en cuanto tal, ser erigida a priori como el límite por fuera del cual no estaríamos ante uno de "los nuestros", es decir, ya no ante un humano propiamente dicho; se trataría de un límite que, por ende, no podríamos permitirnos traspasar sin correr el riesgo de atentar contra lo humano. Pero, partiendo de que mucho de lo que somos capaces de hacer no es, ni ha sido nunca, en realidad, un conjunto fijo e inmodificable de predicados, sino que es objeto de una continua transformación que corre al compás de cada nueva tecnología que con su desarrollo permite realizar acciones que antes nadie hubiera imaginado, para los transhumanistas no cabe entonces suponer que haya una

un argumento que, de paso, sirve ya hoy para defender un eugenismo liberal que no reconoce frontera alguna entre las intervenciones terapéuticas y las intervenciones con fines de mejoramiento, pero deja a las preferencias individuales de los actores del mercado, la escogencia de las finalidades que presiden las intervenciones destinadas a modificar las características genéticas" (Habermas, 2010, p. 35). 
naturaleza humana conforme a la cual se establezcan de manera definitiva los rasgos que permitan determinar por principio cuándo estamos o no frente a un auténtico ser humano, ni menos aún que suponga un infalible freno normativo al cual deba plegarse su proyecto de modificación tecnológica. Así, puesto que la evolución no ha dejado de operar y, por ende, la especie humana que conocemos actualmente no es el término último de la cadena evolutiva, se preguntan: ¿por qué no acelerar las cosas en una dirección libremente escogida que permita a la humanidad, como especie biológica, dar un salto hacia algo distinto y, claro, mucho mejor, ahora que precisamente se cuenta con los medios tecnológicos para conseguirlo?

Sin embargo, la vaguedad en el criterio para deslindar lo curativo o terapéutico de lo mejorativo o aumentativo, en la que se apoyan los transhumanistas, vuelve inevitable la preocupación ética que con frecuencia despierta tal proyecto, acerca de la posibilidad de que emerjan en el futuro castas de humanos mejorados, es decir, grupos privilegiados considerados más plenamente humanos por el hecho de poseer capacidades aumentadas tecnológicamente, $y$, por consiguiente, castas de humanos considerados seres a medias, o incluso, subhumanos, por no tenerlas. Y es que, como advierte el filósofo Hans Jonas "es imperceptible el paso que lleva de aliviar al paciente - una meta perfectamente acorde con la tradición médica- a aliviar a la sociedad de la incomodidad provocada por comportamientos individuales difíciles entre sus miembros" (Jonas, 1995, p. 52). En otras palabras, el ideal transhumanista dibuja en el horizonte una pendiente por la que, según algunos críticos (Sandel, 2009; Fukuyama, 2000), podría resbalarse hacia terribles escenarios de inhumanidad. Las capacidades que hoy solo nos parecen posibles para un ser humano que de manera excepcional haya recurrido a tales técnicas de mejoramiento, con el tiempo podrían llegar a ser consideradas, merced a la utilización masiva y, valga decirlo, a la promoción comercial de dichas técnicas, como los rasgos "normales" a los que cualquier individuo que quiera ser alguien en la sociedad debería aspirar, abriéndose con esto la posibilidad para que -como ya ocurre en el presente con prácticas terapéuticas onerosas- quienes no cuenten con los recursos económicos para acceder a estas mejoras, o simplemente no deseen hacerlo, terminen inevitablemente relegados a una posición de subordinación en el orden social y económico o, como algunos más pesimistas temen, vean su existencia misma amenazada, al ser considerados individuos o grupos anormales de los que la sociedad podría buscar prescindir. Los fantasmas del pasado avivan, pues, la inquietud acerca de que con su programa de mejoramiento humano los transhumanistas terminen alimentando proyectos eugenésicos de los que por experiencia histórica sabemos muy bien a cuanto horror pueden conducir. No extraña entonces que reparos como estos intervengan con frecuencia en los debates éticos acerca de un proyecto que parece decidido a emplear sin cortapisas todo medio tecnológico al alcance para producir seres humanos mejorados o aumentados.

Por su parte, los transhumanistas buscan dar un parte de tranquilidad insistiendo en que a diferencia de tales experiencias catastróficas, su proyecto de mejoramiento 
no es un proyecto de Estado, susceptible de derivar en un régimen totalitario, sino que, en la vena liberal de la que se reivindican, la decisión de mejorarse estará siempre sometida al libre albedrío de cada individuo (Ferry, 2017). Cabe preguntarse, empero, si no pecan por ingenuos al pretender minimizar el enorme poder que el mercado ejerce sobre las elecciones de los individuos y que puede convertir el mejoramiento en un mandato económico sin apelación posible. De cualquier forma, y volviendo al punto que nos interesa, de tener éxito en su empresa, los seres aumentados que preconiza el transhumanismo serían tan distintos a nosotros que, de hecho, su solo prospecto hace dudar de si todavía habrá de llamárselos humanos y no, más bien, como muchos ya vaticinan, "posthumanos", refiriéndose con este término a una especie nueva que solo podrá sobrevenir al precio muy probable de llevar a la extinción a nuestra especie humana.

Ahora bien, es preciso señalar que aunque el término de "transhumanismo" está circulando ampliamente desde hace un buen tiempo, bajo él se cobijan versiones bastante diversas que vuelven difícil delinear con nitidez sus contornos. Así, por ejemplo, algunos autores (Ferry, 2017; Hottois, Missa \& Perbal, 2015) distinguen entre un transhumanismo basado en el empleo de tecnologías cibernéticas que permitirán el desarrollo e implante de prótesis capaces de potenciar las habilidades físicas y cognitivas de los seres híbridos que las portan (ciborgs), mientras ponen en una categoría aparte los proyectos que, basados más bien en las biotecnologías y en técnicas como la edición genética o la biología sintética, se proponen llevar a cabo la modificación del genoma humano con miras a la producción de una nueva especie biológica dotada de capacidades que, según los estándares actuales, habría que juzgar sobrehumanas. A estos últimos reservan el término de "posthumanismo" o de "transhumanismo biológico", por contraste con el "transhumanismo cibernético" que corresponde más bien al primero descrito. A nuestro juicio, sin embargo, entre el uno y el otro la distancia es provisional y más bien de grado. Si bien el segundo transhumanismo (el biológico) se antoja más radical en su ambición, al pretender una transformación de fondo y posiblemente irreversible del equipamiento genético del ser humano, prefigurando, por ende, la partida de defunción de la especie humana como la conocemos hasta hoy, en la práctica resultará muy difícil, si no imposible, deslindar uno de otro. Ciertamente, cabe imaginar que se avance hacia el uso combinado de las nuevas tecnologías con la consiguiente tendencia a hacer converger sus propósitos: veríamos, pues, aparecer ciborgs con prótesis y material genético modificado en su parte orgánica.

De cualquier modo, y a manera de orientación en medio de este paisaje todavía en formación, podemos señalar a Ray Kurzweil (2005) como el representante del transhumanismo en su versión cibernética. Su voz descuella por el tono desafiante y provocador que ha adoptado, al punto de sostener aseveraciones tan chocantes como la de sugerir que en el futuro los seres humanos no modificados podrían servir de alimento para seres humanos aumentados, tal como ocurre actualmente con los animales. Del transhumanismo biológico, y bajo una faceta menos escandalosa, el referente más conocido es seguramente Nick Bostrom del Future of Humanity Institute de Oxford. A 
diferencia de Kurzweil, Bostrom parece atender mejor las críticas que desde distintos ángulos se dirigen al proyecto transhumanista de mejoramiento, mostrando una mayor sensibilidad a los dilemas éticos, sociales, políticos que tales propuestas despiertan en muchos, pero sin restarle fuerza al entusiasmo por un proyecto de mejoramiento que, en todo caso, asume como inevitable (Bostrom, 2011).

De ahí que al referimos al transhumanismo en términos de antropotécnica sirviéndonos de la conocida expresión de Sloterdijk-, apuntemos a lo que el filósofo alemán define como una manera de producirse el ser humano a sí mismo (Sloterdijk, 2006). En efecto, según este autor, si el humanismo puede ser visto como una antropotécnica es porque definió las técnicas cuyo dominio es requerido para entrar a formar parte, a título pleno, de la humanidad o comunidad humana: tales técnicas son, para el humanismo, la escritura y la lectura. Para Sloterdijk, sin embargo, la constatación a la que nos vemos abocados es que estas técnicas se han vuelto actualmente obsoletas para cumplir dicho fin; así, según su perspectiva, el humanismo está condenado. De manera que al hablar del transhumanismo como proyecto antropotécnico entendemos que se trata aquí de proponer una definición radicalmente nueva del ser humano, la cual está estrechamente determinada por técnicas muy diferentes que serán empleadas a partir de entonces para producirlo: las nuevas tecnologías NBIC (Nano-, Bio-, Info- y Ciber- tecnologías). Es evidente que, según esta antropotécnica transhumanista, el ser humano en un sentido más acabado no dependerá del acceso letrado a la gran tradición escrita y a los valores universales en ella transmitidos, sino que lo hará de la posesión de un cuerpo y de una mente aumentados, bien por haber fusionado de modo inseparable su componente orgánico con prótesis cibernéticas, bien por tener un equipamiento genético completamente diseñado para asegurar un nivel superior de desempeño. Así las cosas, ser un mejor humano, o más exactamente, un humano mejorado, supondrá, paradójicamente, ya no ser más un humano, al menos no según lo que dicta la antropotécnica humanista que nos ha producido como humanos hasta ahora. El humano mejorado mediante la antropotécnica transhumanista deberá rendir física, cognitiva y emocionalmente de una forma tan excepcional, que ni el error, ni la enfermedad, ni el sufrimiento, ni siquiera la muerte, puedan hacer sombra a su ilimitado potencial.

Es sabido que el transhumanismo entiende la enfermedad y la muerte como problemas técnicos a los que forzosamente podrá encontrárseles soluciones cada vez mejores a medida que progresen la ciencia y la tecnología a nuestra disposición. De allí que nos parezca que el proyecto transhumanista está fundamentalmente centrado en una manera de entender el cuerpo humano que no solo lo considera plástico y, por ende, transformable, sino que lo concibe, más bien, de forma negativa, como defectuoso, y, en consecuencia, necesitado de perfeccionamiento continuo. A la luz de un objetivo tan ambicioso como acabar con la muerte, no hay duda de que tal imperfección radica en lo que se revela, a sus ojos, como la insoportable vulnerabilidad que lo aqueja y, aún más, su carácter perecedero. Así pues, según confían los pregoneros más entusiastas 
del movimiento, el día llegará en que la enfermedad no podrá acortar la vida humana y la muerte dejará de ser un destino ineluctable (Kurzweil, 2005; Alexandre, 2011). Esos transhumanistas no tienen oídos para sentencias como la de Sócrates que equiparaba la sabiduría humana al aprender a morir. Para ellos la muerte no tiene por qué ser aceptada con resignación revestida de heroísmo, sino que el verdadero heroísmo estará más bien en dar muerte a la muerte.

Como se advierte hasta aquí, para pensar el transhumanismo en clave filosófica se hace necesario examinar con mayor detenimiento la relación que existe entre su

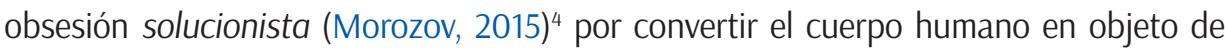
perfeccionamiento continuo, y la concepción de técnica que se halla implícita en tal proyecto. Sin duda, hay buenas razones para pensar que Heidegger, a quien la cuestión de la técnica moderna le mereció tanto de su atención, sabrá brindarnos luces al respecto.

\section{Heidegger y la pregunta por la técnica}

El transhumanismo se hace comprensible como expresión del mundo tecno-científico en el que estamos inmersos. ¿Cómo caracterizar dicho mundo? En él se persigue obsesivamente transformar y no simplemente comprender o conocer la realidad, o, si se quiere, no hay conocimiento que de antemano no esté ya orientado a permitir el dominio y la transformación de lo existente. Una característica de la técnica actual es, ciertamente, la de hacer sistema e integrarse con la ciencia, de allí que se hable propiamente de sistema tecno-científico. Mientras que tradicionalmente la relación entre ciencia y técnica fue entendida de manera que la técnica era definida como ciencia aplicada, es decir, los descubrimientos científicos eran tenidos como el punto de partida posible para desarrollos técnicos posteriores, sabemos hasta qué punto Heidegger consiguió apartarnos de esta comprensión de las cosas (Dusek, 2009). ${ }^{5}$

La cuestión de la técnica, recordémoslo brevemente, dominó buena parte de la reflexión del Heidegger tardío (Pattison, 2000, pp. 54-55), en la medida en que el vínculo

4 Con la palabra "solucionismo", tomada del mundo de la arquitectura y de la planificación urbana, el filósofo bielorruso Evgeny Morozov se refiere a la concepción según la cual la aplicación de la tecnología es vista actualmente como la fórmula mágica capaz de resolver todos los problemas personales y sociales; algo así como la llave universal para disminuir, por ejemplo, los crímenes, la corrupción, la desigualdad, la enfermedad, el sufrimiento, la polución, etc. (Morozov, 2015).

5 Val Dusek muestra cómo la filosofía de la tecnología, en tanto rama o campo de estudio de la filosofía, es de fecha reciente, ya que por mucho tiempo la técnica fue vista como ciencia aplicada y, en ese sentido, al hacer filosofía de la ciencia se creía estar abordando, aunque fuera de manera secundaria, el tema de la técnica. No será sino hasta mediados del siglo XX que la filosofía de la técnica (o de la tecnología) surge como un nuevo campo de estudio. Sin duda alguna la razón tiene que ver mucho con las inquietudes éticas que despiertan las nuevas tecnologías y el poder de transformación y, sobre todo, de destrucción que las caracteriza. Igualmente, según Dusek, la aparición de este campo de estudio se ha hecho posible gracias a los acercamientos cada vez más numerosos entre las dos tradiciones filosóficas contemporáneas: continental y analítica, que pueden unir sus esfuerzos para pensar un fenómeno que tiene muchas dimensiones entreveradas: epistemológica, ética, política, etc. (Dusek, 2009, pp. 131-145). 
entre metafísica y técnica se le fue revelando estrecho e indisociable. En efecto, para el filósofo de la Selva Negra, la técnica no se deja pensar en su verdadera esencia como un hacer del ser humano, es decir, como un instrumento humano puesto al servicio de fines también humanos. La lectura que hace de la técnica un rasgo antropológico (lectura que en cuanto medio le atribuye a la técnica un carácter neutro, siendo el fin perseguido el que desde fuera determina su valor), si bien no es un enfoque incorrecto, se queda, a sus ojos, en un nivel de aproximación superficial, al que se le escapa nada menos que la esencia de la técnica. Bien vista, entonces, la técnica se revela a Heidegger como una forma de verdad o des-ocultamiento (a-letheia) de lo ente:

La técnica no es pues un mero medio, la técnica es un modo de salir de lo oculto. Si prestamos atención a esto se nos abrirá una región totalmente distinta para la ciencia de la técnica. Es la región del desocultamiento, es decir, de la verdad. (...) La técnica es un modo de hacer salir de lo oculto. La técnica esencia en la región en la que acontece el hacer salir lo oculto y el estado de desocultamiento, donde acontece la aletheia, la verdad (Heidegger, 1994, pp. 15-16).

Efectivamente, en la medida en que la esencia de la técnica consiste en llevar de lo oculto a lo desoculto, tal modo de ser vale tanto para la técnica antigua como para la moderna. Sin embargo, a diferencia de la técnica antigua que, según Heidegger, desoculta el ente como objeto (Gegenstand), la moderna, por su parte, ocasiona que lo ente emerja y salga del ocultamiento como existencia (Bestand), entendiendo la palabra como sinónimo de bien o de recurso (Heidegger, 1994). Los entes no salen, pues, a la luz, no se dejan pensar como objetos sino como existencias que, en cuanto tales, están Ilamadas a ser acumuladas, almacenadas, distribuidas, intercambiadas y consumidas. A esto Heidegger lo denomina, haciendo -como él mismo reconoce- algo de fuerza al sentido habitual del término alemán: Ge-stell, traducido por lo general como "estructura de emplazamiento". Tengamos en mente que, en su uso corriente, el término se refiere a una estantería, un andamiaje o un esqueleto. De acuerdo con esto, la técnica moderna es una suerte de marco u orden ontológico en el que se emplaza cada existencia dentro de una estructura totalizante, de tal modo que cada una entra en relación con todas las otras con la finalidad de servir como una especie de combustible para el funcionamiento del conjunto. Heidegger afirma, en efecto, que la técnica moderna provoca (herausfordert) -expresión que sugiere violencia o fuerza-a la naturaleza para que dé, dé y dé energía (Heidegger, 1994).

En virtud de esto, Heidegger puede argumentar, para nuestra sorpresa inicial, que la técnica moderna antecede a la ciencia moderna. Por supuesto, no lo dice porque se le hubiera escapado que los fundamentos de la física moderna se establecieron mucho tiempo antes de que se produjera su aplicación técnica, sino porque el modo de desocultamiento del ente que hizo posible la ciencia moderna era ya él modo propio de desocultamiento que caracteriza a la técnica moderna. Desde sus comienzos, la física moderna estaba, pues, orientada a pensar técnicamente la naturaleza, es decir: 
como un entramado de fuerzas medibles, calculables, acumulables, etc. El ente en su totalidad comparece desde entonces como recurso, depósito, reserva de la cual se busca extraer su energía, en el ciclo sin fin que alimenta e impulsa el dispositivo técnico. Esto es lo que explica la tesis, a primera vista sorprendente, según la cual la ciencia es ya esencialmente técnica.

Ahora bien, Heidegger advirtió con mucha clarividencia que en la era técnica nuestra suerte como seres humanos podría ser la de quedar reducidos, a nuestro turno, a la condición de simples existencias o recursos, condición a la cual reducimos a nuestra vez - provocados, es verdad, por el ser mismo- la totalidad de lo ente. Este es el peligro que, según él percibe, crece como un desierto, y no es otro que la pérdida de nuestra humanitas. Un peligro que, paradójicamente, encierra también la salvación. Ese peligro es visto con crudeza en las siguientes líneas de la obra Superación de la metafísica, que bien pueden ser leídas como una "profecía" sobre el transhumanismo:

Siendo el hombre la más importante de las materias primas, no extrañará que un día, sobre la base de investigaciones de químicos contemporáneos, se construyan fábricas para la producción artificial de esta materia prima. Los trabajos del químico Kuhn (...) abren ya la posibilidad de organizar y de regular, siguiendo las necesidades de la producción, los seres vivos machos y hembras (Heidegger, 1994, p. 85).

Y es que lo característico del mundo técnico en el que vivimos no reside, para Heidegger (Heidegger, 1994), en la omnipresencia de las máquinas o de los dispositivos electrónicos en todos los ámbitos de la cotidianidad, sino en el ser humano que dicha época produce y que a su vez la produce a ella. Vistas así las cosas, la transformación moderna del mundo en un mundo técnico tiene que ver ante todo con la comprensión ontológica que lo revela todo, incluido al ser humano, dentro de una estructura totalizante de recursos. De suerte que el peligro no proviene solamente de la violencia que los humanos hacemos, por ejemplo, al medio ambiente, mediante el uso desbocado de máquinas cada vez más potentes e infalibles en su extracción de recursos, sino que es ante todo una exigencia, una provocación, en fin, una suerte de requisición que pronto nos hacemos también a nosotros mismos, al transformarnos cada vez más en meros recursos humanos emplazados en el marco del dispositivo técnico.

Es verdad que por momentos la retórica heideggeriana sobre la técnica parece cercana a la de un conservatismo antimoderno, de estirpe agraria y rural (como el que expresó en su momento cierta ala del Nazismo con la que él mismo se identificó). Pero no se trataría en lo absoluto para Heidegger de que sucumbamos a cierta nostalgia romántica, denigrando y rechazando en actitud ludita los adelantos técnicos que atestigua el presente. Entender la esencia de la técnica debe llevar a comprender, según él, cuán ingenuo sería pretender escapar de ella -aislados en lo alto de una montaña sin wifi, por ejemplo-, así como abrazarla sin reserva sería una miopía. La libertad en nuestro trato con ella se juega, de acuerdo con el pensador de Friburgo, en la capacidad que tengamos para balancearnos 
entre un decir a veces "sî" y otras veces "no" a la técnica. Así pues, escribe en Serenidad en un tono que se nos antoja bastante mesurado:

Podemos decir "sí" al inevitable uso de los objetos técnicos y podemos a la vez decirles "no" en la medida en que rehusamos que nos requieran de modo tan exclusivo, que dobleguen, confundan y finalmente devasten nuestra esencia. (...) Pero si decimos simultáneamente sí y no a los objetos técnicos, ¿no se convertirá nuestra relación con el mundo técnico en equívoca e insegura? Todo lo contrario, se hará simple y apacible. (...) Quisiera denominar esta actitud que dice simultáneamente "sí" y "no" al mundo técnico con una palabra antigua: serenidad (Gelassenheit) (Heidegger, 2001, p. 28).

Esta fórmula, lejos de favorecer una ambivalencia o vacilación frente al peligro advertido, pone de presente la necesidad de resistirse a él, evitando que el modo de desocultamiento técnico sea el único modo que aceptemos de desocultar el ente. En otras palabras, el llamado está a hacer convivir con, o mejor, contra la mirada técnica dominante, una mirada distinta que, en contraste, deja ser al ente sin más, esto es, sin provocación. Por lo tanto, la advertencia que hace el filósofo es a que evitemos caer ingenuamente en la oposición fácil entre tecnofobia y tecnofilia, ya que cualquiera de las dos actitudes sería el signo de una falta evidente de comprensión acerca de la verdadera esencia de la técnica, la cual se ha revelado, no como un neutro hacer humano, sino como una forma de dárse-nos a pensar lo que es; un destino al que nos aboca nuestra humanidad.

De manera que la resistencia que estaría a nuestro alcance cultivar frente a lo que de todas formas tememos como un desenfreno latente en la técnica moderna -el espacio posible para la salvación, si cabe hablar así-, pasa por evitar sucumbir a la hegemonía del pensar calculante que es propia del mundo técnico. Esto implica desarrollar la que podríamos Ilamar una nueva "pedagogía del ver", gracias a la cual aprendamos a dejar ser o aparecer el ente al mismo tiempo dentro y fuera del marco o estructura ontológica del emplazamiento en la que únicamente se desoculta o muestra como recurso explotable. En fin, el esfuerzo ha de estar en preservar la posibilidad que como humanos tenemos de experimentar otro pensamiento, uno que escapa al puramente calculador, a saber: un pensamiento meditante.

Dicho lo anterior, ¿hay otro modo de explicar el obsesivo afán de perfeccionamiento del que previamente hemos hablado en el transhumanismo, que no sea por cuenta de esta relación unidimensional con lo ente en la que solo cuenta lo que, en último término, no es sino recurso: cuantificable, medible, utilizable y explotable? No parece, en verdad, que sea posible explicarlo de otra forma. El humano aumentado o perfeccionado que promete el transhumanismo se dice, precisamente, aumentado, en función de la mayor capacidad que se espera alcance a desarrollar para tener un mejor desempeño cognitivo y afectivo, sea lo que sea que esto signifique. Él mismo será así un recurso más eficiente. Y, ¿no es, en efecto, desocultado nada más que como recurso, provocado únicamente 
para producir un rendimiento continuo, como el ser humano termina deshumanizado, reducido a mero cuerpo susceptible de aumento, en fin, reducido a un ente entre entes, como advertía Heidegger?

Si se presta atención a esta acusación que, con Heidegger, puede dirigirse al transhumanismo, en el sentido de que reduce el ser humano al plano de lo óntico y, todavía más, lo convierte en mero recurso energético del cual busca extraer cada vez más su potencial de rendimiento, no podemos dejar de advertir la afinidad que puede emparentar dicho rechazo con el que cualquier humanismo tradicional (p. ej., el humanismo cristiano o el liberal) les haría también a los transhumanistas, juzgando como indebida la reducción del ser humano a su simple condición de viviente. Porque, ¿no se supone acaso que el ser humano, en cuanto que humano, es necesariamente algo distinto que un ser biológico? ¿Algo más que un cuerpo viviente? ¿Más que solo organismo? Ciertamente, una postura humanista tradicional podría plantearlo en estos términos: a nuestro ser viviente u orgánico se añade un atributo de naturaleza distinta e inconmensurable, de valor superior y trascendente, por cuenta del cual somos realmente humanos. No es, por ende, el hecho de ser vivo y de tener un cuerpo el que define de manera esencial nuestra humanidad, sino algo distinto y ontológicamente superior de lo que también participamos. Pero, ¿es esto lo que también plantea Heidegger?

Teniendo en cuenta la importante crítica al humanismo de Heidegger, nada parecería menos consecuente que atribuirle a él esta misma postura. Y, sin embargo, es evidente que su pensamiento da cuenta de una dificultad para lidiar con el carácter viviente y corpóreo del ser humano, dificultad que parece aflorar de manera aún más decisiva cuando desde su perspectiva filosófica tratamos de elaborar una aproximación crítica al transhumanismo. De allí que resulte apremiante enfocarnos sobre la corporeidad humana y preguntarnos qué supondría posar sobre ella una mirada que no sea técnica, como la del transhumanista. Esta es la pregunta a la que debemos dar paso.

\section{El cuerpo humano: más allá de una mirada técnica}

El ser humano que el transhumanismo se propone dejar atrás es el resultado de azares acumulados durante millones de años de evolución de la vida en la tierra. En cuanto ente que está sujeto a las leyes biológicas que rigen en el planeta, el ser humano es concebido como un viviente de naturaleza análoga a la de todo organismo animal, de suerte que la diferencia entre ambos sería tan solo de grado -como lo sostuvo Darwin para escándalo de sus contemporáneos-; lo que nos separa de los animales es un tramo más o menos pequeño a escala evolutiva, y definitivamente no un misterioso salto cualitativo que irrumpe en el orden del universo. Sin embargo, aunque somos animales como los demás, para los transhumanistas, los seres humanos hemos conocido un progreso tan excepcional que no solo hemos conseguido -gracias principalmente a la ciencia moderna- entender nuestra condición evolutiva, sino que, además, habríamos 
desarrollado los medios tecnológicos que permiten conducir dicha evolución en la dirección que mejor nos plazca. Ciertamente, la narrativa transhumanista más común dirá que ha sido gracias al progreso científico y tecnológico que la especie humana ha llegado a la posición de la que disfruta en el presente, de poder asumir el control de su evolución, para ya no dejar al azar, sino al diseño premeditado, el curso que habrá de seguir nuestra especie. Estos progresos tecno-científicos le brindarían al ser humano, como nunca antes en su historia, los medios para emprender el perfeccionamiento continuo de su condición como organismo viviente, permitiéndole incluso acariciar la posibilidad de que en el futuro, con tales avances prometeicos, Ilegue a hacer el quite definitivo a la muerte.

Aunque esta exaltación de las soluciones técnicas y la naturalización del ser humano sugieren una ruptura importante del transhumanismo con respecto a discursos humanistas tradicionales, conviene señalar, sin embargo, que en la medida en que este proyecto se ampara en ideales de perfeccionamiento y de mejoramiento ilimitados de la condición humana, existe -como algunos autores lo han notado también- un vínculo que lo liga, con solución de continuidad, con el humanismo tradicional (Hottois, 2016). La indeterminación esencial del ser humano y su consiguiente potencial para hacer de sí mismo lo que decida libremente ser, como cantaba en su loa a la dignidad humana el renacentista italiano Pico della Mirandola (Della Mirandola, 2013), ha sido una confianza presente en los humanismos clásicos, la cual se mantiene operando en el transhumanismo.

De otro lado, así como los distintos humanismos que hasta ahora han desfilado por los corredores de la historia occidental han dado muestras de un sesgo de carácter gnoseocéntrico, que consiste en hacer descansar lo propiamente humano en la posesión de ciertas facultades cognitivas superiores, así también esta convicción sigue implícitamente presente en el transhumanismo. Se ha llamado la atención sobre lo paradójico que resulta el deseo de perfeccionamiento continuo característico del transhumanismo, pues si bien ese deseo invita a ser visto como expresión inequívoca de una adoración desmedida del cuerpo - posición que lo situaría al margen de las tradiciones religiosas, espiritualistas y humanistas que han privilegiado lo no-corporal-, en él se escondería más bien un desdén o desprecio tácito por el cuerpo, en la medida en que el transhumanista, al igual que los humanistas tradicionales, no escapa del todo al hecho de ver en el cuerpo un lastre u obstáculo del que habría que depurarse lo más posible, en aras de acercarse a un ideal de sujeto humano puramente racional o de conocimiento (Lecourt, 2011). ${ }^{6}$ Así pues, menos que una adoración, lo que revela tal

6 En un sentido similar se pronuncia Martin Weiss cuando afirma lo siguiente: "The posthumanist -or genuily humanist- position forgets the constitutive contingency of the human being, as this position is latently based on the idea that the human body is only the accidental substratum of the essentially free spiritual subject. This is because, if he thinks that the free subject is something different from his physical incarnation, it is possible to identify control over the 
deseo ascético es más bien una visión negativa del cuerpo, en la medida en que, como decíamos atrás, se lo entiende como intrínsecamente defectuoso para llevar a cabo la verdadera tarea humana que es la de conocer. En suma, si se ansía tanto mejorarlo es precisamente por la incomodidad que genera, reducido como está desde el comienzo a la condición de simple vehículo o soporte material para el despliegue de facultades cognitivas de índole más elevada.

Ahora bien, sabemos lo crítica que es la posición de Heidegger respecto al humanismo. En la célebre Carta sobre el humanismo cuestiona, precisamente, la tendencia de los diversos humanismos históricos a pensar el ser humano en primera instancia como un viviente, si bien, y con la idea de otorgarle una dignidad superior, se apresuran luego a revestirlo de una facultad extraordinaria y exclusiva. Le atribuyen, en efecto, el logos o la razón, para de ese modo situarlo por fuera y por encima del resto de vivientes: animal sí, pero racional (Heidegger, 2009). En lugar de una exaltación de su humanidad, Heidegger ve en este gesto un movimiento degradante que no sitúa la dignidad del ser humano en un nivel lo suficientemente alto como le corresponde:

se puede afirmar que el único pensamiento es el de que las supremas determinaciones humanistas de la esencia del hombre todavía no llegan a experimentar la auténtica dignidad del hombre. (...). Pero esta oposición no significa que semejante pensar choque contra lo humano y favorezca a lo inhumano, que defienda la inhumanidad y rebaje la dignidad del hombre. Sencillamente piensa contra el humanismo porque éste no pone la humanitas del hombre a suficiente altura (Heidegger, 2009, p. 38).

Así pues, para el filósofo alemán el punto de partida humanista y metafísico para pensar el ser humano es errado, ya que lo concibe desde su animalitas y no de su humanitas. Este comienzo encubre la esencia del ser humano y no puede más que llevar a un extravío de consecuencias peligrosas. De ahí sus ingentes esfuerzos por remarcar la distancia entre el ser humano y el animal, la cual es, según la califica, de carácter abismal. Ninguna comparación es posible entre uno y otro, pues mientras aquél es Dasein, existencia, apertura al ser, comprende el ente en cuanto (als) ente; el animal, por el contrario, es tan solo un ente más que carece por completo de esta apertura y comprensión; no se trata sino de un puro viviente (ein nur Lebendes). ${ }^{7}$

body with liberation of the subject. Thus underlying the humanist/posthumanist positions is an unconscious dualism of mind and body" (Weiss, 2014, p. 329).

7 El pasaje que a continuación citamos in extenso deja ver cómo en la Carta sobre el Humanismo, Heidegger subraya con fuerza el carácter insuperable de la distancia que a su juicio separa el Dasein del animal (y de lo vivo en general). Ella reside en la capacidad que distingue al primero, y de la que carece el segundo, de corresponder al advenimiento del ser en cuanto tal, lo que le confiere un estatuto que lo acerca más del lado de lo divino que de lo viviente, con el que, si bien se encuentra emparentado, lo está en mucho menor grado: "De entre todos los entes, presumiblemente el que más difícil nos resulta de ser pensado es el ser vivo, porque, aunque 
La misma idea vuelve ampliamente en Conceptos fundamentales de la metafísica (Heidegger, 2004) donde Heidegger desarrolla la conocida tesis según la cual "el animal es pobre de mundo" (weltarm), por contraste con el Dasein que es "configurador de mundo" (Weltbilden), y ambos están muy lejos de la piedra que es simplemente "sin mundo" (weltlos). A diferencia del Dasein, afirma allí el filósofo - sin la intención, según él, de establecer ninguna jerarquía entre ambos- el animal no entra en relación con lo que es en cuanto que es: no configura mundo, lo que, en cambio, es lo propio del Dasein. La del animal, por el contrario, es una manera de ser en la que dicha relación no es en lo absoluto posible, en tanto el animal esté siempre como preso y aturdido (Benommenheit) por lo que encuentra dado en su entorno y a lo que, en realidad, está inevitablemente atado sin posibilidad de darle un sentido propio. La piedra sobre la que descansa el tigre, aclara, no es nunca una piedra para él. Heidegger considera que el animal está en cierto modo diseñado para ejecutar un repertorio fijo de respuestas ante lo que le rodea, conductas que son gatilladas por lo que llama el "anillo desinhibidor" y que está compuesto por aquel círculo de entes que, por decirlo así, entran en el campo de relevancia para la supervivencia del animal. Esto le impide a Heidegger considerar que su comportamiento sea algo diferente a una reacción de tipo más bien instintivo.

En este horizonte de reflexión adquiere sentido aquella afirmación suya tan llamativa que, como sabemos, levantó la sospecha de Derrida (1990), según la cual solamente el ser humano tiene, en sentido estricto, mano. Para Heidegger, la mano sería propia del ser humano en cuanto Dasein. De suerte que por muy cercanas que nos parezcan las manos humanas y las garras del simio sobre un plano morfológico y funcional, entre ellas no hay, según nuestro filósofo, absolutamente nada en común. No cabe duda de que semejante afirmación causa gran extrañeza, leída, como no podemos evitar hacerlo, desde el punto de vista biológico evolutivo que hoy en día, en pleno siglo XXI, damos prácticamente por descontado. Desde esta perspectiva, la distancia que separa a una de otra es apenas en grado de complejidad. Para Heidegger, en cambio, la distancia entre la mano humana y la garra del simio es inmensa, puesto que entraña una diferencia que no es tan solo cuantitativa, sino de naturaleza -si nos permitimos la libertad de atribuirle hablar en esos términos metafísicos tradicionales-. La mano del Dasein abre o da mundo, mientras que la segunda no es más que un instrumento útil

hasta cierto punto es el más afín a nosotros, por otro lado está separado de nuestra esencia exsistente por un abismo. Por contra, podría parecer que la esencia de lo divino está más próxima a nosotros que la sensación de extrañeza que nos causan los seres vivos, entendiendo dicha proximidad desde una lejanía esencial que, sin embargo, en cuanto tal lejanía, le resulta más familiar a nuestra esencia existente que ese parentesco corporal con el animal que nos sume en un abismo apenas pensable. Semejantes reflexiones arrojan una extraña luz sobre la caracterización habitual, y por eso mismo todavía demasiado prematura, del ser humano como animal rationale. Si a las plantas y a los animales les falta el lenguaje es porque están siempre atados a su entorno, porque nunca se hallan libremente dispuestos en el claro del ser, el único que es «mundo»" (Heidegger, 2009, p. 9). 
para la supervivencia del organismo animal en su entorno. Asoma aquí un rasgo que con buenas razones estamos tentados a calificar de antropocéntrico en la manera que tiene de aproximarse a la diferencia humano/animal, puesto que se toma lo humano como el punto de referencia para pensar el modo de ser del animal, modo de ser que es definido en términos de cierta privación respecto al humano.

Esto no implica, empero, que la mano humana no pueda, como los análisis de Heidegger (Heidegger, 1992, p. 84-85) sobre la máquina de escribir así lo sugieren, dejar de ser mano. Es decir, dejar de configurar mundo. Es posible que la mano desaparezca allí donde, por decirlo de algún modo, se ve anexada a un instrumento como la máquina de escribir, de la que la mano termina convertida más bien en su apéndice (Ihde, 2010). En un sentido similar avanza la observación de Byung-Chul Han cuando teme, a tono con Heidegger, que la mediación constante de las pantallas a la que asistimos actualmente en la era digital haya hecho que nuestras manos se enfrenten cada vez menos a lo que el autor coreano llama "la negatividad del mundo", esto es: a su materialidad irreductible y su resistencia impenetrable. Por la mediación constante de las etéreas y lisas pantallas, nuestras manos quedan circunscritas cada vez más a ser un simple instrumento de tecleo, es decir, un medio para obtener, acumular y distribuir el preciado recurso de la información (Han, 2014, pp. 61-62). ${ }^{8}$

De manera que, por lo dicho hasta aquí, hacer justicia al modo de ser humano en lo que tiene de más propio significa, según Heidegger, evitar reducirlo ónticamente a la condición de organismo viviente y reclama pensarlo ontológicamente como lugar de apertura o "claro del ser", esto es, como Dasein (Heidegger, 2009). Por esta razón, la aspiración transhumanista de que el mejoramiento técnico del cuerpo pueda en algún sentido perfeccionarlo como humano, carecería de cualquier sentido. Antes bien, al entenderlo técnicamente como simple recurso optimizable -como parece que lo entiende el transhumanismo- se corre directo hacia su deshumanización. Desde una perspectiva inspirada en Heidegger, convertirlo en un ente más dentro de un dispositivo diseñado para obtención de resultados, como pieza emplazada en el gran engranaje que es el Ge-stell, sería su ocaso como propiamente humano. Y, según parece, este paso funesto se hace casi inevitable si se lo piensa ante todo como siendo un viviente más, ya que de esa manera se estaría allanando el camino para reducirlo a un cuerpo susceptible, técnica mediante, de cumplir proezas de rendimiento.

8 Han escribe al respecto: "La mano es, en Heidegger, el medio para el «ser», que designa la fuente originaria del sentido y la verdad. La mano que escribe comunica con el «ser». La máquina de escribir, en la que solo se emplea la punta de los dedos, nos aleja del ser: La máquina de escribir vela la esencia del escribir y de la escritura. Ella sustrae del hombre el rango esencial de la mano, sin que él experimente debidamente esta sustracción, y reconozca que aquí acaece-propicia ya". Una transformación de la referencia del ser a la esencia del hombre. La máquina de escribir conduce a una atrofia de la mano, a la decadencia de la mano que escribe, es más, al olvido del ser. Sin duda, Heidegger habría dicho que el aparato digital empeora aún más esta atrofia de la mano" (Han, 2014, pp. 61-62). 
Parece así que el proyecto transhumanista confirma la idea de Heidegger de que al concebirnos como meros vivientes abrimos la puerta a nuestra deshumanización, integrados como terminamos al dispositivo técnico o Ge-stell en el que todo lo que es queda emplazado como recurso maximizable. Nos pondríamos así al borde del precipicio, al arriesgar olvidar por completo el olvido metafísico de nuestra esencia como "pastores del ser", Ilamados a co-responder a su acontecer. Pero -y es aquí donde parece imponerse a nosotros la necesidad de dar un giro más allá de la reflexión de Heidegger sobre la relación entre humanitas y esencia de la técnica-, ¿qué hacer con el hecho de que, en un sentido que el filósofo alemán quizás no está dispuesto a admitir, nos sentimos hoy más que nunca parte, y nada más que parte, del mundo de lo vivo, compartiendo un mismo destino? Lo cierto es que no puede menos que reprochársele a Heidegger el que no haya ofrecido una mirada más conciliadora del Dasein con su naturaleza viviente y orgánica, de forma que su filosofía pudiera entrar en un diálogo más directo con las ciencias naturales y con lo que éstas tienen para decir sobre nuestra condición humana.

Una queja frecuente frente al trabajo de Heidegger -en especial desde el campo de la fenomenología (i. e., Merleau-Ponty) - apunta a que no haya prestado más atención a este tema. No se entiende bien, por ejemplo, que en Ser y tiempo no haya expandido su concepción del Dasein para incluir en ella al cuerpo humano como estando orgánicamente conectado con la naturaleza y con formas de vida más primitivas (Aho, 2010). ${ }^{9}$ A este respecto es importante señalar, empero, que en tiempos más recientes se ha venido matizando mucho la lectura que señala el descuido de Heidegger sobre el tema el cuerpo, en buena medida gracias a la mayor atención que entre sus estudiosos han ganado los conocidos Seminarios de Zollikon (Heidegger, 2001), en donde el filósofo alemán se ocupó extensamente del cuerpo y, sobre todo, del carácter corporificado (embodied) de la ex-istencia humana. El tema adquirió allí enorme relevancia por tratarse, precisamente, de un prolongado seminario realizado a intervalo de varios años con un grupo de psiquiatras suizos, encabezados por el Dr. Medard Boss, a quienes Heidegger deseaba familiarizar con su filosofía, de modo que ella les brindara luces nuevas acerca de la naturaleza de la enfermedad psíquica y de su tratamiento. Su interés era llevarlos a abandonar

9 Según sus críticos, en efecto, habría faltado en Heidegger el paso de ver en el cuerpo un existenciario (Existential) o estructura esencial del Dasein. Aho comenta: "What these criticisms tend to suggest is that Heidegger's Project is missing an explicit recognition of how body participates in shaping our everyday understanding of things". Sin embargo, este comentarista argumenta en su libro en una dirección bastante distinta, tratando de explicar por qué dicha ausencia no constituye una negligencia sino que, antes bien, es coherente con el proyecto filosófico de Heidegger visto en su conjunto, el cual es ante todo un proyecto ontológico acerca de cómo pensar el ser. Y añade que, contrario a quienes creen que Heidegger despreció el tema, el filósofo alemán no solo no desestimó su importancia sino que incluso habría reconocido que el cuerpo es el "problema más difícil" de pensar ("the most dificult problem") (Aho, 2010, p. 3). 
cualquier residuo de una concepción dualista mente-cuerpo para pensar la unidad psicosomática del ser humano. ${ }^{10}$

Con todo, podemos preguntarnos hasta dónde nos ayuda en verdad Heidegger a pensar el transhumanismo y a responder cabalmente ante los posibles excesos del mismo. Sin duda, su reflexión sobre la esencia de la técnica permite señalar el grave peligro de deshumanización que conlleva la pretensión de aumentar tecnológicamente al ser humano, so pretexto de que sus "recursos" no han sido hasta ahora plenamente aprovechados. Pero, por otro lado, ¿cómo prestar oído a una voz tan a contracorriente, no solo con respecto a un enfoque evolutivo ampliamente aceptado en nuestros días, sino también muy alejada de la experiencia que hacemos cada vez más en estos tiempos de crisis ambiental, de nuestra pertenencia esencial al mundo de lo vivo? ¿No es la suya, al fin y al cabo, una concepción profundamente antropocéntrica que insiste -como buena parte de la tradición occidental- en situar al ser humano en un registro óntico completamente distinto y separado del resto de entes, antropocentrismo que está ampliamente cuestionado en la filosofía reciente? En fin, ¿no se hace necesaria, más allá de Heidegger, una reconsideración del carácter radicalmente viviente del ser humano, que permita confrontar la instrumentalización del cuerpo humano preconizada por el proyecto transhumanista, así como desmontar el antropocentrismo humanista? Esta es precisamente la tarea que queda abierta.

En efecto, el filósofo alemán insistió en que solamente podríamos encontrar una respuesta adecuada al fenómeno de la técnica al hilo de la reflexión sobre su esencia. Si es así, parece entonces que lo salvífico de pensar el transhumanismo en clave heideggeriana estaría en la oportunidad que esto nos brinda de advertir los límites de su filosofía frente a la manera de pensar nuestra condición de seres vivientes, corpóreos, más aún, de pensar la humanidad de nuestro cuerpo; algo que Heidegger pudo no estar en condiciones de considerar por completo debido a su recelo, sin duda comprensible, frente al posible reduccionismo biologicista del ser humano (como el que de hecho ocurre en el transhumanismo), reduccionismo que, por otro lado, deja a la vista la necesidad de un pensamiento capaz de ir más al fondo del misterio que entraña nuestra condición de seres vivientes.

10 En dicho seminario Heidegger hace afirmaciones que, como la siguiente, matizan cualquier tendencia a creer que el cuerpo juega para él un papel apenas secundario en la capacidad del Dasein de comprender lo que significa ser y de configurar mundo: "Bodying forth belongs to being-in-the-world, which is primarily the understanding-of-being. Therefore, this [understanding-of-being] is not just something still added to bodying forth. A bodying forth always coparticipates [mitbeteiligt] in the experience of what is present. However, presencing itself is not a bodying forth. A bodying forth also co-participates in the receiving-perceiving of what is present, even if it is addressed silently" (Heidegger, 2001, p. 200). 


\section{Referencias}

Aho, K. (2010). Heidegger's Neglect of the Body. NY: SUNY.

Alexandre, L. (2011). La mort de la mort: Comment la technomédecine va bouleverser l'humanité. Paris: Lattes.

Aristóteles. (2002). Física. Madrid: Editorial Gredos.

Bostrom, N. (2011). Una historia del pensamiento transhumanista. Argumentos de Razón Técnica, 14, 157-191.

Della Mirandola, P. (2003). Discurso sobre la dignidad del hombre. Buenos Aires: Longseller.

Derrida, J. (1990). La main de Heidegger. En Heidegger et la Question (pp. 173-222). Paris: Flammarion.

Dusek, V. (2009). Philosophy and Technology. En J. K. B. Olsen, S. A. Pedersen \& V. F. Hendricks (Eds.), A Companion of Philosophy of Technology (pp. 131-145). Oxford: Blackwell Publisher.

Ferry, L. (2017). La revolución transhumanista. Cómo la tecnomedicina y la uberización del mundo van a transformar nuestras vidas (A. Martorell, Trad.). Madrid: Alianza Editorial.

Fukuyama, F. (2000). Our Posthuman Future. Consequences of Biotechnology Revolution. NY: Farrar, Straus \& Giroux.

Habermas, J. (2010). El futuro de la naturaleza humana. ¿Hacia una eugenesia liberal? Barcelona: Paidós.

Han, B.-C. (2014). En el enjambre. Barcelona: Herder.

Heidegger, M. (1992) Parmenides. Bloomington and Indianapolis: Indiana University Press.

Heidegger, M. (1994). La pregunta por la técnica. En Conferencias y artículos (pp. 9-37) (E. Barjau, Trad.). Barcelona: Ediciones del Serbal.

Heidegger, M. (2001). Serenidad (I. Zimmermann, Trad.). Barcelona: Ediciones del Serbal.

Heidegger, M. (2004). Conceptos fundamentales de la metafísica. Mundo, finitud, soledad. Madrid: Alianza Editorial.

Heidegger, M. (2009). Carta sobre el humanismo (H. Cortés \& A. Leyte, Trad.). Madrid: Alianza Editorial.

Hottois, G. (2016). ¿El transhumanismo es un humanismo? (J. V. Bonilla Pardo, Trad.). Bogotá: Universidad El Bosque.

Hottois, G., Missa, J.-N., \& Perbal, L (2015). L’humain et ses préfixes. Une encyclopédie du transhumanisme et du posthumanisme. Paris: Vrin. https://doi.org/10.18270/rcb.v8i2.871

Hunyadi, M. (2018). Le temps du posthumanism. Un diagnostic d'époque. Paris: Les Belles Lettres. Huxley, J. (1957). Transhumanism. En New Bottles for New Wine (pp. 13-17). London: Chatto \& Windus. 
Ihde, D. (2010). Heidegger's Technologies. Postphenomenological Perspectives. NY: Fordham University Press. https://doi.org/10.5422/fso/9780823233762.001.0001

Jonas, H. (1995). Principio de responsabilidad. Ensayo de una ética para la civilización tecnológica. Barcelona: Herder.

Kurzweil, R. (2005). The Singularity is Near. When Humans transcend Biology. NY: Viking.

Lecourt, D. (2011). Humain, posthumain. Paris: PUF. https://doi.org/10.3917/puf.lecou.2011.02

More, M. (2013). Letter to Mother Nature. En: More, M. \& Vita-More, N. (Eds.), The Transhumanist Reader. Classical and Contemporary Essays on Science, Technology, and the Philosophy of the Human Future (pp. 449-450). New Jersey: Wiley- Blackwell.

Morozov, E. (2015). La locura del solucionismo tecnológico. Buenos Aires: Katz.

Pattison, G. (2000). The Later Heidegger. London: Routledge.

Sandel, M. (2009) The Case against Perfection: Ethics in the Age of Genetic Engineering. Cambridge/London: Belknap Press. htps://doi.org/10.2307/j.ctvz80mc

Sloterdijk, P. (2006). Normas para el parque humano. Una respuesta a la «Carta sobre el humanismo» de Heidegger. Barcelona: Siruela.

Weiss, M. (2014). Posthuman Dignity. En: The Cambridge Handbook of Human Dignity (pp. 320-331). UK: Cambridge University Press. 